Revista Bioética

\title{
ATUALIZAÇÃO
}

\section{Secularismo, pós-modernidade e justiça na assistência à saúde em Engelhardt}

Artur Mamed Cândido ${ }^{1}$, Ricardo Alcântara ${ }^{1}$, Volnei Garrafa ${ }^{1}$

1. Programa de Pós-Graduação em Bioética, Faculdade de Ciências da Saúde, Universidade de Brasília, Brasília/DF, Brasil.

\section{Resumo}

Este artigo tem por objetivo analisar conceitos centrais do pensamento de Hugo Tristram Engelhardt Junior. Inicialmente são introduzidos os principais elementos de sua argumentação, com ênfase na maneira como o autor percebe a bioética, considerando o fracasso do projeto filosófico moderno e sua concepção original de "estranhos morais". Em seguida, o estudo procura interpretar o posicionamento de Engelhardt quanto à moralidade e à justiça na distribuição dos recursos de saúde. Ao final, critica-se a concepção marcadamente ultraliberal do autor, que, ao se colocar no extremo do espectro do liberalismo, nega qualquer dever moral do Estado em prover assistência à saúde. Palavras-chave: Bioética. Secularismo. Alocação de recursos. Princípios morais. Consenso.

\section{Resumen}

\section{Secularismo, posmodernidad y justicia en la asistencia sanitaria en Engelhardt}

Este artículo tiene como objetivo analizar los conceptos centrales del pensamiento de Hugo Tristram Engelhardt Junior. Inicialmente, se introducen los principales elementos de su argumento, con énfasis en la forma en que percibe la bioética, considerando su concepción original de "extraños morales" y el fracaso del proyecto filosófico moderno. Al final, se critica a la concepción marcadamente ultraliberal del autor, que al situarse en el extremo del espectro del liberalismo niega cualquier deber moral del Estado en la atención en salud.

Palabras clave: Bioética. Secularismo. Asignación de recursos. Principios morales. Consenso.

\begin{abstract}
Secularism, postmodernity and justice in healthcare in Engelhardt

This study presents and critically analyzes the main conceptual aspects of the moral thinking of US physician and bioethicist Hugo Tristram Engelhardt Jr. Initially, the theoretical elements that frame Engelhardt's arguments are introduced, emphasizing how the author perceives the status of bioethical morality in postmodernity, including the "failure of the modern philosophical project" and his original notion of "moral strangers". After addressing these epistemological aspects, the study examines Engelhardt's position on morality and justice in the allocation of healthcare resources. Finally, Engelhardt's ultraliberal approach is critically analyzed, concluding that by putting himself at the radical end of the liberal spectrum, he denies the State any moral duty to play a role in healthcare provision.

Keywords: Bioethics. Secularism. Resource allocation. Morals. Consensus.
\end{abstract}

Declaram não haver conflito de interesse. 
Médico, filósofo e professor de filosofia da Universidade do Texas em Austin, o estadunidense Hugo Tristram Engelhardt Junior (1941-2018) dedicou parte considerável de sua vida acadêmica a compreender a condição moral do homem pós-moderno, apontado os reflexos dessa condição no campo da bioética. Segundo o autor, o contexto histórico-cultural da pós-modernidade é marcado pelo fracasso do projeto iluminista, que ansiava pelo advento da moralidade comum, de base racional, capaz de unir todos os povos sob a égide de princípios universais, proporcionando soluções pacíficas para conflitos ${ }^{1}$.

Diante do malogro do projeto filosófico moderno, Engelhardt afirma que, no campo da bioética, o papel da racionalidade e da moralidade secular se reduz à rara linguagem da comunicação pacífica entre estranhos morais ${ }^{2}$. A partir desses pressupostos, o autor construiu suas considerações sobre a distribuição de recursos na assistência à saúde.

Neste trabalho, as aproximações ao pensamento de Engelhardt assumem caráter marcadamente crítico. Ao apresentar pontos essenciais das ideias do autor sobre a moral na contemporaneidade e seus efeitos na justiça distributiva em saúde, sustentam-se algumas críticas às suas posições filosóficas e políticas, que parecem anacrônicas e destoantes das atuais teorias de justiça.

\section{Status da bioética na pós-modernidade}

Ao tomar o fracasso do projeto filosófico da modernidade como determinante da moralidade contemporânea, Engelhardt afirma ser inviável impor uma ética secular canônica ${ }^{1}$. Para o autor, a condição do ser humano pós-moderno se traduz na experiência de viver em uma cultura pós-cristã, imerso em ruínas de instituições morais e fragmentos de um modo de vida anteriormente íntegro ${ }^{1,3}$. Assim, a pós-modernidade seria marcada pela pluralidade de concepções e pela ausência de moral religiosa e metafísica intacta ${ }^{1}$.

A humanidade pós-moderna se depara com questões fundamentais, mas que não podem ser respondidas satisfatoriamente no contexto secular em que são suscitadas. A pós-modernidade então seria marcada pela derrocada da moralidade secular canônica, e é justamente esse fracasso que Engelhardt define como a catástrofe fundamental da cultura (...) contemporânea ${ }^{4}$. A divergência e a fragmentação moral também repercutem no campo da bioética, que se ocupa de conflitos éticos relacionados a sexualidade, geração de filhos, sofrimento, tratamento prestado aos pacientes, estabelecimento de instituições de assistência à saúde, justiça na alocação de recursos médicos e enfrentamento da morte.

A bioética se insere no cenário "cacofônico" que Engelhardt descreve. A pluralidade desafia a ideia de que há uma bioética secular preenchida de conteúdo moral racionalmente validado e, por isso, universalmente aceito. Vive-se atualmente em meio a sobras fragmentadas de visões e de interpretações morais que antes eram vibrantes e integradas ${ }^{5}$, e na bioética não é diferente. Restam apenas fragmentos que poderiam ter proporcionado narrativas essenciais sobre políticas apropriadas de assistência à saúde.

Nesse panorama desolador, coube a Engelhardt assumir o compromisso de garantir o único objetivo que acreditava possível: pensar uma ética que considere as fronteiras do raciocínio moral secular ${ }^{6} \mathrm{sem}$ a imposição coercitiva de visões igualitárias do que é politicamente correto. Resguardando ideais liberais e valores como a autonomia e o individualismo, Engelhardt toma para si a tarefa de defender a pluralidade - que considera natural e saudável - dos chamados "estranhos morais" - pessoas e comunidades que adotam visões essencialmente diversas. Dessa forma, argumenta a favor da privatização de compromissos e formas de bioéticas ${ }^{7}$ plurais em relação à perspectiva dos empreendimentos sociais coercivos de grande escala. Como exemplo desses empreendimentos, o autor cita os projetos modernizantes dos Estados seculares, como o marxismo ${ }^{1,8}$.

Engelhardt pontua que o Ocidente foi o primeiro a aspirar de modo sistemático a ver a realidade a partir da perspectiva anônima da razão, do logos, de qualquer pessoa, para articular uma visão normativa de qualquer lugar e fora de qualquer história particular ${ }^{9}$. O autor lembra que tal projeto já era concebido desde a Antiguidade por pensadores como Heráclito, Platão e Aristóteles, que buscavam explicar racionalmente o ser e a moralidade. Mesmo o cristianismo ocidental supôs, em vários momentos, que a moral podia ser reconhecida e compreendida por meio da razão, sem que fosse necessário recorrer ao expediente da fé ${ }^{1}$.

O projeto moral moderno teve seu ápice no lluminismo, quando ganhou força a aspiração a uma moralidade comum, capaz de unir todos os povos e proporcionar paz perpétua ${ }^{1}$. Os pensadores iluministas nutriam esperanças de que seria possível, por meio da razão, descobrir um denominador comum, revelando padrões morais uniformes. Neste sentido, as esperanças numa moralidade comum foram desviadas de um encontro com Deus e com a graça para 
um encontro secular racional, com realidade que todas as pessoas pudessem compartilhar ${ }^{10}$.

Engelhardt ${ }^{1}$ enfatiza que todas as tentativas históricas de justificar a ética secular falharam. Segundo ele, em suas várias expressões, as esperanças do projeto moderno se concentraram no exame da própria razão, das simpatias humanas ou de outros elementos de nossa condição, buscando revelar o que nos une em comunidade e estabelecer uma interpretação moral comum dos conflitos sociais. Contudo, nos vários contextos em que esse projeto foi aplicado, verificaram-se gradações no papel da racionalidade ou das simpatias, sensibilidades e sentimentos comuns, impondo-se sempre a dificuldade de determinar qual razão deveria orientar a moral e qual simpatia deveria ser canônica ${ }^{1}$.

Interpôs-se sempre a dificuldade de estabelecer a objetividade das obrigações e direitos em relação a preferências morais. Na presença de diferentes interpretações e premissas, as controvérsias se mostraram insolúveis pelo argumento racional, ficando clara a necessidade de definir um padrão para julgar, ordenar e comparar o que está moralmente em jogo ${ }^{1}$. Como resultado, a humanidade pós-moderna partilha da paradoxal experiência de viver em uma época na qual muitos sentem saudades da Idade Média e, ao mesmo tempo, desejam evitar a crença em Deus, aspirando à descoberta da bioética secular, capaz de proporcionar orientações para uma política assistencial particular ${ }^{11}$.

Segundo Engelhardt ${ }^{1}$, o argumento racional se mostra incapaz de silenciar as controvérsias sobretudo no encontro de estranhos morais. É principalmente nesse campo de divergência que o projeto moderno falha em conceber narrativa sobre a ação e a moral tão profunda quanto aquela provida pela moralidade essencial, metafísica e religiosa, pois, no contexto secular, as virtudes são esvaziadas de essência moral ${ }^{12}$.

O autor mostra-se pessimista quanto à capacidade da pós-modernidade de solucionar dilemas bioéticos. O colapso do projeto iluminista resulta no fracasso da reivindicação epistemológica de que podemos saber, por meio da razão, o que devemos fazer $^{13}$. São inúteis, para o autor, os esforços de construir uma moralidade racionalmente fundamentada, pois poucas preocupações a respeito da virtude e do caráter poderiam ser compreendidas em termos seculares gerais, fora de comunidades morais particulares.

A bioética secular seria incapaz de desenvolver argumentos para proibir ações que comunidades como a cristã consideram profundamente desviadas do ponto de vista moral, como o suicídio ou a eutanásia de recém-nascidos com comprometimentos vitais severos. Nesse campo, a bioética dará sempre respostas qualificadas, deixando, contudo, grandes e perturbadoras áreas de incerteza ${ }^{14}$. Essa falta de univocidade moral inviabilizaria a autoridade moral necessária para definir políticas públicas em geral e políticas de assistência à saúde em particular. Por isso, Engelhardt defende que comunidades particulares devem ter a liberdade para moldar as interpretações morais substantivas com seus próprios membros ${ }^{14}$.

Para o autor, é preciso apreciar a enormidade do fracasso do projeto do lluminismo na tentativa de descobrir moralidade essencial ${ }^{15}$. Esse colapso pesa sobretudo contra as teorias de justiça e explicações da moralidade, que colocam em questão toda a bioética secular, uma vez que, se não é possível justificar a moral comum, então não é possível justificar reivindicações gerais do que seria (i)moral:

Se não podemos descobrir um método objetivo de decidir quando os moralmente desviados são também moralmente errados, então, a ação dos moralmente odiosos e santos será igualmente justificável ou não passível de distinção, pelo menos em termos seculares gerais. Estaremos, portanto, à beira do niilismo (...) Deus está morto na área pública secular (...) $e$, dado que um substituto secular não está disponível em uma moralidade canônica essencial, passível de descoberta, não existem restrições morais gerais. $A$ bioética em seu projeto secular, está em ruínas ${ }^{16}$.

\section{Estranhos morais e moral secular}

Engelhardt distingue a bioética secular da bioética de compromisso moral essencial. A segunda seria puramente continuísta; nela, as pessoas transferem aos esforços comuns a autoridade moral do consentimento ${ }^{1}$. Mesmo na pós-modernidade, permanecem e resistem inúmeras comunidades morais desse tipo. Nesse contexto, surgem os estranhos morais, pessoas que não partilham premissas ou regras morais de evidência e inferência suficientes para resolver suas controvérsias morais por meio de sadia argumentação racional, ou que não têm compromisso comum com os indivíduos ou instituições dotadas de autoridade para resolvê-las ${ }^{17}$.

Existem diferenças reais entre visões morais, que fundamentam interpretações substancialmente diversas de bioética. Essa variedade surge das diferentes premissas e regras dos participantes da 
controvérsia. Desse modo, disputas entre estranhos morais não poderão ser solucionadas por sadios argumentos racionais ou pelo recurso a autoridade comumente reconhecida. É essa incapacidade de resolver conflitos (exceto pelo acordo) que assinala a distância entre estranhos morais, mesmo quando a distância não é emocionalmente percebida, e ainda que os atores consigam construir relação harmônica de convivência e cooperação mútua.

Engelhardt ${ }^{1}$ assevera que a diversidade moral não é atraente e pode até ofender. Ter crenças particulares é atrair julgamentos. O autor alerta que no mundo contemporâneo a coação ainda resiste à pluralidade. $\mathrm{Na}$ assistência à saúde, muitas vezes o próprio Estado secular empreende ações para anular a diversidade. Assim, reconhecer os estranhos morais é também reconhecer os limites da autoridade moral secular.

Entre estranhos morais, o valor da tolerância deve ser ressaltado, mas "tolerar" não significa que as comunidades morais precisam deixar de condenar atos que consideram repreensíveis. Engelhardt recorda que, na verdade, a tolerância só faz sentido em relação ao que cada um de nós considera errado e impróprio ${ }^{1}$. Contudo, para além dessa atitude, o autor reforça que mesmo aqueles que acreditam em religião e ideologias devem reconhecer que uma bioética secular proporciona o quadro pacífico, e neutro, por meio do qual uns podem atingir os outros ${ }^{2}$. $\mathrm{Na}$ ausência de acordo essencial, somente a moralidade secular geral pode oferecer espaço dialógico capaz de transpor abismos e permitir a colaboração.

É neste ponto que Engelhardt mostra algum otimismo quanto ao projeto da bioética secular, que permitiria a estranhos morais dialogar pacificamente ${ }^{3}$. Pois somente a moralidade secular proporcionaria discurso capaz de ser compartilhado mesmo com aqueles de que se discorda profundamente. Trata-se de criar linguagem única que pode ser falada nas ruínas do fracasso do lluminismo e diante da tragédia do compromisso moral fragmentado ${ }^{18}$.

As discordâncias não podem ser remediadas pela análise e pelo argumento racional, mas apenas pela conversão à comunidade moral. Nessas circunstâncias, é preciso tolerar muitas coisas que se julga profundamente erradas. Assim, a bioética secular não serve como orientação para viver a vida; pelo contrário, significa uma moralidade que seja capaz de vincular pessoas que sejam "estranhos morais" (...) para que se encontrem e colaborem pacificamente, já que isso é o pouco que podem compartilhar pessoas provenientes de distintas comunidades morais e portadoras de visões diferentes sobre o mundo e seus valores ${ }^{19}$.
Autoridade moral, consentimento e beneficência

Para Engelhardt ${ }^{1}$, a bioética é campo marcado por tensões, como a que nasce da diferença entre respeitar a liberdade e garantir o melhor interesse das pessoas - em outras palavras, o conflito entre a permissão ou consentimento e a beneficência. Do contraste entre esses princípios derivam os dilemas fundamentais da saúde, como aborto, obediência ao tratamento médico e recusa da assistência.

$\mathrm{Na}$ pós-modernidade, a autoridade entre estranhos morais pode brotar somente do consentimento, isto é, mesmo em circunstâncias complexas, a raiz da autoridade é a permissão, e não argumentos racionais ou crenças comuns ${ }^{1}$. Mulheres e homens sensatos só poderão estabelecer moralidade comum por meio do acordo mútuo. Nestes termos, Engelhardt defende o consentimento como princípio ético geral que deve regular a conduta em sociedade plural.

O princípio da beneficência define que a finalidade da ação moral é alcançar o bem e evitar prejuízos. Contudo, em sociedade pluralista nenhuma definição pode ser estabelecida como canônica. Nas diversas comunidades morais que a compõem, a própria noção de "bem" nasce de complexa teia de interpretações. Em razão das várias perspectivas, não se pode deduzir uma moralidade secular geral a partir da beneficência, ainda que o compromisso com esse princípio seja importante, visto que sem ele a vida moral não tem essência ${ }^{1}$.

Assim, é pelo consentimento, e não pela coerção, que estranhos morais podem se encontrar nas ruínas do racionalismo. Do acordo mútuo deriva a autoridade e o poder que defendem vítimas da força não fundada no consentimento ${ }^{1}$. Em suma, o autor defende que a ética, nas ruínas do projeto iluminista, deve ser concebida consequentemente como um meio de assegurar a autoridade moral através do consentimento em face de intratáveis controvérsias morais substanciais ${ }^{15}$.

O consentimento representa, assim, a única fonte da autoridade moral na pós-modernidade, justamente porque não há moralidade substancial particular. A comunidade secular moral é, portanto, composta de pessoas que aceitam colaborar entre si. A ética fundada no consentimento pode fazer o que a força, a conversão e a razão secular não podem: unir estranhos morais. 
Direito à saúde em Engelhardt

Demonstrados seus principais conceitos, cumpre fazer algumas considerações sobre como Engelhardt enfrenta a questão da moralidade na distribuição dos recursos de saúde. Nesse campo, fica patente que o autor adota perspectiva ultraliberal, negando veementemente a existência do direito à saúde - em posição que muito contrasta com a realidade jurídica de países como o Brasil, que reconhece esse direito em sua Constituição Federal ${ }^{20}$. Nesse sentido, sua perspectiva se alinha com o ideário estadunidense mais clássico, que aproxima o tema da justiça em bioética à preservação da autonomia do indivíduo.

Engelhardt pensa a justiça como garantia da autonomia individual e, por isso, defende que a saúde deve ser tratada de maneira semelhante a outros bens e serviços, regidos pelas leis do livre mercado, de modo a garantir a oferta. Para o autor, a imposição de sistema universal e gratuito é moralmente injustificável, pois representaria ato coercivo, de zelo ideológico, totalitário, que deixa de reconhecer a totalidade de visões morais que combinam com os interesses em assistência à saúde, os limites morais seculares e da autoridade do Estado e a autoridade dos indivíduos sobre si mesmos e suas propriedades. É um ato de imoralidade secular ${ }^{21}$.

O filósofo, portanto, nega que a saúde seja direito humano. Para ele, não há direito moral secular à saúde, nem mesmo a assistência com padrões mínimos de qualidade. A proposta de política idealmente igualitária estaria, na sua perspectiva, fundada em compromisso impossível e incoerente, pois não poderia, ao mesmo tempo, oferecer a melhor assistência a todos, garantir a igualdade entre prestadores e usuários (que o autor chama de "fornecedores" e "consumidores") e conter custos. Para Engelhardt, esse esforço estaria enraizado no fracasso em enfrentar a finitude da autoridade moral secular, da visão moral secular, dos poderes humanos diante da morte e do sofrimento, da vida humana e dos recursos financeiros humanos ${ }^{22}$.

Em lugar da universalidade, o autor defende um sistema de saúde que reconheça as limitações morais e financeiras do fornecimento de assistência, considerando a desigualdade no acesso (...) como moralmente inevitável, por causa dos recursos privados e da liberdade humana ${ }^{22}$, e aceitando que há um preço para salvar a vida humana. Estes seriam pré-requisitos básicos para o estabelecimento de sistemas de saúde economicamente eficientes, estabelecidos por recursos comunitários ${ }^{22}$.

\section{Engelhardt e o pensamento liberal}

Dentre as exíguas funções que a doutrina liberal delega ao Estado, destaca-se a garantia dos direitos individuais contra ataques de terceiros e agentes do próprio Estado. Arnsperger e Van Parijs resumem o conteúdo do liberalismo afirmando que o ponto de partida (...) é a dignidade fundamental de cada pessoa, que não pode ser burlada em nome de nenhum imperativo coletivo. Esta dignidade reside no exercício soberano da liberdade de eleição no marco de um sistema coerente de direitos ${ }^{23}$.

Para liberais como Engelhardt, um Estado com mais funções do que defender a liberdade individual viola o direito do cidadão de não ser compelido a fazer certas coisas, como contribuir para um sistema de saúde universal. Segundo Nozick ${ }^{24}$, para Engelhardt o aparato coercitivo estatal não pode ser usado para obrigar alguns cidadãos a ajudar outros ou para proibir atividades visando o bem e a proteção do próprio indivíduo.

Engelhardt nega a existência do direito à saúde em sentido positivo ou prestacional, defendendo que não se pode justificar direitos subjetivos ante o poder público em matéria de assistência sanitária - posição repelida pela Constituição brasileira, que considera a saúde direito do cidadão e dever do Estado $^{20}$. Contudo, é importante ressaltar que, como ocorre com quase todas as doutrinas políticas, no liberalismo há largo espectro de perspectivas, que vão das mais radicais às mais brandas, e a posição de Engelhardt é das mais extremadas.

Allen Buchanan ${ }^{25}$, por exemplo, fala em dever de beneficência, matizando propostas mais radicais do liberalismo ao reconhecer um mínimo sanitário decente. No entanto, tal concepção não deriva do princípio da justiça nem importa no reconhecimento do direito à saúde, mas se funda em sentido de dever moral de caridade ou beneficência da sociedade como um todo ${ }^{26}$. Assim, haveria compromisso geral de caridade a ser coordenado pelo Estado, mas que não justificaria qualquer tipo de coerção estatal sobre os cidadãos.

Já o liberalismo igualitário incorpora certos princípios de justiça distributiva e considera a assistência à saúde como direito. Esta corrente, orientada por teorias de justiça, admite que o Estado, mediante políticas coercitivas, está moralmente autorizado a ativar políticas distributivas. Como afirma Thomas Nagel ${ }^{27}$, a característica principal dessa vertente é a defesa de relação adequada entre liberdade e igualdade, sem priorizar qualquer desses ideais. 
O desenvolvimento do liberalismo igualitário deve muito a John Rawls ${ }^{28}$, com a publicação de Uma teoria da justiça. A posição original do autor é um giro copernicano no liberalismo. A partir dele, são várias as tentativas de justificar o direito a assistência estatal à saúde, muito embora o próprio Rawls não a inclua no pacote de necessidades básicas.

Outra concepção é a de "seguro prudente", de Ronald Dworkin ${ }^{29}$, que, aplicada à assistência, levanta três questões cruciais: 1) quanto deve gastar o Estado em saúde; 2) que nível de atenção médica a sociedade deve oferecer a seus cidadãos; e 3) que nível mínimo de atenção à saúde é justo fornecer a todas as pessoas, inclusive as mais pobres. Dworkin enxerga a saúde como direito, mas rejeita o "princípio do resgate" que orienta a distribuição dos recursos em algumas sociedades. Tal princípio se sustenta em dois critérios: a vida e a saúde são os bens mais importantes e, portanto, tudo o mais deve ser sacrificado em seu nome; e a saúde deve ser distribuída equitativamente. Esse princípio conduziria à aplicação de todos os recursos nacionais na atenção sanitária, um projeto impossível ${ }^{29}$.

Como alternativa, Dworkin propõe o "princípio do seguro prudente", com a adoção do "mínimo necessário". Para isso, o autor estabelece três condições: 1) o sistema econômico distribuiria recursos com base na "justa igualdade"; 2) informações sobre custo, efeitos secundários e utilidade de tratamentos, procedimentos e medicamentos estariam ao alcance do público em geral; e 3) ninguém incluindo as companhias de seguro de saúde - teria informações sobre antecedentes e probabilidade de alguém contrair alguma doença ou sofrer acidentes, de maneira a evitar discriminação ${ }^{29}$.

É evidente a influência da "posição original" de Rawls ${ }^{28}$, cuja intenção básica é estabelecer imparcialidade nos critérios de justiça distributiva. Assim, Dworkin constrói espécie de posição original na qual não haveria desigualdades sociais e as pessoas elegeriam o pacote de seguro de saúde que pudessem pagar, tendo em conta o custo de oportunidade desses recursos médicos para elas.

Dworkin sugere regulação obrigatória, ou escoIhas forçadas, nos casos em que escolhas livres são prejudicadas por externalidades e outras imperfeições de mercado. Inspirado no princípio da correção, o seguro hipotético seria estratégia para possibilitar oportunidades iguais e evitar riscos. Daí o adjetivo "prudente", aludindo à decisão pessoal conforme critérios de oportunidade e racionalidade em posição original ${ }^{30}$.

Um seguro estatal compulsório não deveria assegurar tratamentos caríssimos, seja porque as pessoas não esgotariam seus recursos na compra da apólice, seja porque o benefício final seria duvidoso ${ }^{30}$. Dworkin pretende levar as pessoas a se perguntar que parâmetros orientam os gastos em saúde, considerando critérios de justiça e racionalidade econômica ${ }^{23,29}$. A principal contribuição do autor é chamar atenção para consequências não econômicas de incapacidades e enfermidades graves, que deveriam ser mitigadas em modelo igualitário de justiça.

Já Norman Daniels ${ }^{31}$ destaca a relação entre justiça e saúde. O autor aplica a teoria de Rawls com duas finalidades: 1) reconhecer que a sociedade tem o dever de proporcionar a seus membros parte justa e adequada do total dos recursos sociais relacionados com o bem-estar; e 2) garantir a justa distribuição de serviços sanitários, considerando as distintas necessidades.

Dado que doença e incapacidade são restrições não merecidas, que limitam as oportunidades da pessoa de alcançar suas metas, Daniels ${ }^{31}$ propõe sistema de saúde baseado na regra da justa igualdade de oportunidades. Seguindo esse princípio, ninguém deve ter benefícios sociais baseados em condições vantajosas não merecidas (porque ninguém é responsável por tê-las), e a ninguém devem ser negados benefícios sociais em razão de condições desvantajosas não merecidas (porque tampouco são responsáveis por essas situações). A atenção à saúde, portanto, deve operar pela regra de compensação para aqueles em desvantagem ${ }^{31}$. Como critério para determinar quais necessidades de saúde são devidas, Daniels ${ }^{31}$ propõe o critério de "funcionamento normal da espécie", considerando como objeto de assistência sanitária todos os desvios da organização funcional natural do ser humano típico.

Engelhardt desconsiderou todas as contribuições do liberalismo igualitário e outras abordagens mais modernas da justiça mesmo nas edições mais recentes de sua obra. Uma teoria da justiça, de Rawls $^{28}$, foi publicada em 1971, 15 anos antes da primeira edição de Fundamentos da bioética ${ }^{1}$, em 1986. A tradução brasileira foi baseada na edição de 1996, e não se enxerga qualquer concessão - ainda que no seio do liberalismo - à questão da justiça na distribuição dos recursos de saúde, e é certo que Engelhardt escreveu conhecendo a obra de Rawls, pois o cita diversas vezes ${ }^{1,28}$.

Em certo momento, ao inserir a sorte individual na discussão sobre o cálculo do direito à saúde, Engelhardt apega-se a distinção já presente em Rawls para extrair conclusões surpreendentes. Por um lado, haveria certa "loteria natural" relativa a circunstâncias fortuitas provocadas por forças naturais; por outro, uma "loteria social", que expressaria mudanças 
decorrentes da ação humana. A partir deste ponto de vista, as desigualdades entre indivíduos seriam fruto do acaso, podendo ter raiz natural ou social e, portanto, não poderiam ser reputadas como injustas de modo a se tornar objeto de compensação ${ }^{1}$.

A desigualdade então aparece como fato moralmente inevitável, que não geraria obrigação secular, clara e manifesta, de ajudar os necessitados ${ }^{1}$. Dado que ninguém é responsável pela má fortuna de outrem, o Estado não estaria obrigado a mobilizar recursos de seus cidadãos para ajudar enfermos que não podem pagar por assistência à saúde. Doentes e incapacitados reclamariam nossa simpatia e até nossa caridade, mas seu infortúnio não poderia ser encargo de todos.

Não se podem converter as necessidades em direitos ${ }^{32}$, conclui Engelhardt, eximindo a sociedade de qualquer compromisso moral em relação aos resultados das loterias sociais e naturais. E o autor vai ainda mais longe em sua posição radical, defendendo que não deve haver qualquer coerção estatal baseada em pretendida justiça social, que define como desonesta e demagógica.

\section{Considerações finais}

O pensamento de Engelhardt quanto à distribuição dos recursos de saúde denuncia o compromisso do autor com ideologia ultraliberal, em nome da qual o filósofo defende autonomia e liberdades individuais e denuncia a coerção dos Estados seculares. Sua proposta de bioética parte da constatação da morte do projeto moral iluminista, apontando a divisão entre estranhos morais em sociedades plurais para eleger o consenso como fonte exclusiva da autoridade moral.

Engelhardt exacerba o valor da autonomia, ao passo que veicula percepção atrofiada de justiça. A concepção de liberdade individual adotada por ele nega inscrições e condicionamentos sociais dos sujeitos. Seu liberalismo radical se assenta no respeito absoluto à propriedade privada e na distribuição de recursos conforme a capacidade contributiva (ou de pagamento) de cada um. Assim, a assistência à saúde não seria exceção às regras do mercado e do consenso dos "pagantes", ficando a cargo, no caso daqueles que não podem pagar o seguro médico, da caridade livre e espontânea de agentes que decidem autonomamente com quem, com quanto e em que condições contribuir.

Reconhecemos o valor das análises de Engelhardt sobre o pluralismo moral e a sociedade secular, que busca o consenso entre estranhos morais. Contudo, o autor não sustenta suficientemente seu modelo liberal de assistência em detrimento da universalidade. Primeiro, é preciso lembrar que a moralidade não requer necessariamente a validação de metafísica religiosa. Ela pode ser o resultado complexo da interação de diversos fatores, como costumes, afetos, cosmovisões (não necessariamente de caráter religioso) e valores compartilhados entre indivíduos.

Se, conforme apregoa o autor, comunidades particulares devem ter liberdade para moldar interpretações morais, elas não precisam recorrer aos fundamentos da metafísica religiosa. A ausência de fé comum não invalida a construção e a negociação de valores e códigos morais compartilhados, como as noções de direitos humanos e dignidade da pessoa que fundamentam os sistemas jurídicos do Ocidente. No lugar da proposta de Engelhardt, pode vicejar diálogo racional e consensual sobre os ideais societários e humanísticos e concepções partilhadas e racionais de bem comum.

As comunidades morais podem estabelecer amplos territórios de consenso sobre os melhores meios para alcançar seus interesses em saúde. A partir de seu contexto e realidade particular, podem decidir como gerir o bem do maior número de pessoas, conforme a representação que fazem desse bem. Assim, pode-se, por exemplo, julgar moralmente aviltantes os efeitos do liberalismo professado por Engelhardt.

Ao julgar moralmente inaceitável que pessoas sem condições de pagar por plano de saúde sejam lançadas à própria sorte, comunidades morais podem assumir projeto de assistência pública em que a coletividade e as relações de solidariedade sejam postas acima de interesses individuais. Tais comunidades consentiriam no chamado ao Estado para assumir o compromisso de prover condições mínimas de saúde. A determinação desse mínimo pode ser condicionada a cálculos materiais, à negociação de valores e ao sacrifício que cada membro da comunidade esteja disposto a fazer em favor da coletividade, sem prejuízo da percepção de autonomia dos cidadãos.

Buscando delimitar as fronteiras de uma bioética secular que julgou esvaziada de valores, Engelhardt concebe uma ética fundada na hipertrofia de valores individualistas. $O$ autor extrapola a defesa da autonomia, deixando flagrante seu compromisso com as formas mais radicais e desumanas do liberalismo, pautadas na supremacia da propriedade em relação ao bem comum.

Assim, parece ter concebido uma ética alheia aos ideais de justiça, igualdade de oportunidades e interesses coletivos, desconsiderando os efeitos 
dessas políticas na vida da população mais pobre para aderir a visão meritocrática rasa, que ignora o princípio da equidade. Ao defender a distribuição dos recursos com base em loterias sobrenaturais, omitindo as consequências das desigualdades sociais para a saúde, a filosofia moral de Engelhardt, apesar de sua integridade teórica, merece o escaninho das apostas perdidas.

Trabalho desenvolvido na disciplina Fundamentos de Saúde Pública, do Programa de Pós-Graduação em Bioética da Cátedra Unesco de Bioética da Universidade de Brasília.

\section{Referências}

1. Engelhardt HT Jr. Fundamentos da bioética. São Paulo: Loyola; 2008.

2. Engelhardt HT Jr. Op. cit. p. 507.

3. Engelhardt HT Jr. Fundamentos da bioética cristã ortodoxa. São Paulo: Loyola; 2003.

4. Engelhardt HT Jr. Op. cit. 2008. p. 34.

5. Engelhardt HT Jr. Op. cit. 2003. p. 43.

6. Engelhardt HT Jr. Op. cit. 2008. p. 13.

7. Engelhardt HT Jr. Op. cit. 2008. p. 14.

8. Madrid R. La bioética de Tristam Engelhardt: entre la contradicción y la postmodernidad. Rev. bioét. (Impr.) [Internet]. 2014 [acesso 27 maio 2019];22(3):441-7. DOI: 10.1590/1983-80422014223026

9. Engelhardt HT Jr. Op. cit. 2008. p. 23-4.

10. Engelhardt HT Jr. Op. cit. 2008. p. 63.

11. Engelhardt HT Jr. Op. cit. 2008. p. 39.

12. Engelhardt HT Jr. Op. cit. 2008. p. 41.

13. Engelhardt HT Jr. Op. cit. 2008. p. 129.

14. Engelhardt HT Jr. Op. cit. 2008. p. 45.

15. Engelhardt HT Jr. Op. cit. 2008. p. 68.

16. Engelhardt HT Jr. Op. cit. 2008. p. 99.

17. Engelhardt HT Jr. Op. cit. 2008. p. 32.

18. Engelhardt HT Jr. Op. cit. 2008. p. 507.

19. Garrafa V. Apresentação à edição brasileira. In: Engelhardt HT Jr. Fundamentos da bioética. São Paulo: Loyola; 1998. p. 7-11. p. 8.

20. Brasil. Constituição da República Federativa do Brasil de 1988. Diário Oficial da União [Internet]. Brasília, 5 out 1988 [acesso 27 maio 2019]. Disponível: https://bit.ly/3fDMXPs

21. Engelhardt HT Jr. Op. cit. 2008. p. 447.

22. Engelhardt HT Jr. Op. cit. 2008. p. 450.

23. Arnsperger C, Van Parijs P. Ética econômica e social. São Paulo: Loyola; 2003. p. 43.

24. Nozick R. Anarquia, Estado e utopia. Rio de Janeiro: Jorge Zahar; 1991.

25. Buchanan AE. A right to a decent minimum of health care. Philos Public Aff [Internet]. 1984 [acesso 27 maio 2019];13(1):55-78. Disponível: https://bit.ly/3a8FE1o

26. Buchanan AE. Op. cit. p. 57.

27. Nagel T. The problem of global justice. Philos Public Aff [Internet]. 2005 [acesso 27 maio 2019];33(2):113-47. DOI: 10.1111/j.1088-4963.2005.00027.x

28. Rawls J. Uma teoria da justiça. Brasília: Editora Universidade de Brasília; 1981.

29. Dworkin R. Sovereign virtue: the theory and practice of equality. Cambridge: Harvard University Press; 2000.

30. Dworkin R. Sovereign virtue revisited. Ethics [Internet]. 2002 [acesso 2 set 2020];113(1):106-43. DOI: $10.1086 / 341579$

31. Daniels N. Just health care. New York: Cambridge University Press; 1985.

32. Engelhardt HT Jr. Op. cit. 2008. p. 401.

\section{Participação dos autores}

Artur Mamed Cândido e Ricardo Alcântara esboçaram, organizaram e desenvolveram o estudo e redigiram o artigo. Volnei Garrafa orientou o estudo e a realizou a revisão final.

\section{Correspondência}

Artur Mamed Cândido - SQS 410, bloco D, apt. 102, Asa Sul CEP 70276-040. Brasília/DF, Brasil.

Artur Mamed Cândido - Doutorando - mamed.artur@gmail.com

(iD) 0000-0003-1818-7021

Ricardo Alcântara - Doutorando - ricardoalcantara@hotmail.com

(i) 0000-0002-2933-3373

Volnei Garrafa - Doutor - garrafavolnei@gmail.com

(iD) $0000-0002-4656-2485$ 